\title{
How can an IT organization earn its customers' trust: A practical approach
}

\author{
Alexander N. Biryukov \\ E-mail: anbiryukov@fa.ru
}

Financial University under the Government of the Russian Federation

Address: 49, Leningradskiy Prospect, Moscow 125993, Russia

\begin{abstract}
The paper describes a practical approach which can be used by internal IT organizations to gain their business customers' trust. The variety of customers of the internal IT service provider is limited to internal customers only. The distinguishing feature of the proposed approach is that it is completely practice-oriented, i.e. primarily aimed at building trust among IT service providers and their customers in a particular organization. The approach is based on the idea that there are measurable prerequisites for the emergence of a customer's trust which allow you to partially formalize the IT organization's intention to earn its customers' trust. A model of intra-organizational trust is proposed; it is progressively improved as the IT organization develops its trust-building capabilities. The model comprises all IT service customers in an organization along with their communications and accounts for internal organizational IT service market specifics. A high-level blueprint of the trust model is described which can serve as a starting point when developing a full-scale trust model in a particular IT organization. We present an approach to the trust model improvement which builds upon principles adopted from widely recognized CMMI model. With this approach, an internal IT service provider can benefit from maturity assessment methods to improve its trust building capabilities.
\end{abstract}

\section{Graphical abstract}

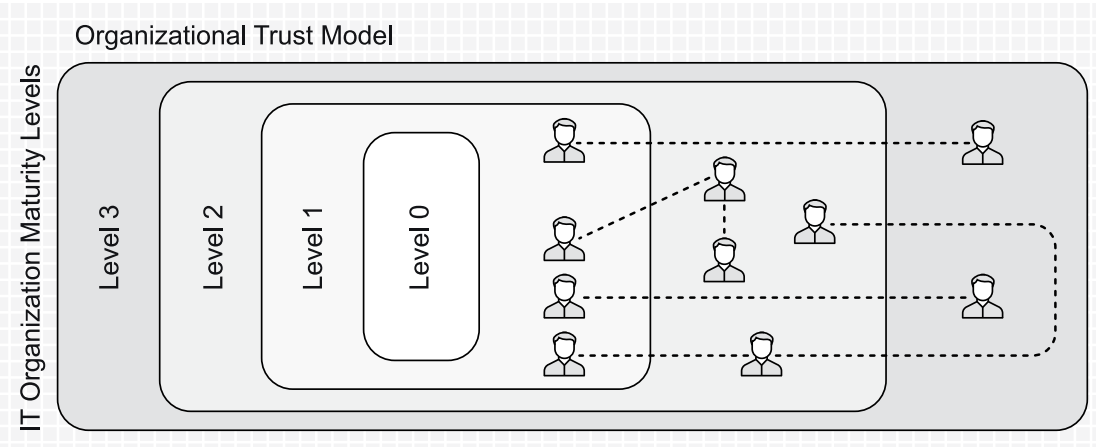


Key words: IT service provider; internal IT service market; trust; IT organization; trust criteria; intra-organizational trust model; trust management; earning trust; maturity; capability level.

Citation: Biryukov A.N. (2019) How can an IT organization earn its customers' trust: A practical approach. Business Informatics, vol. 13, no 3, pp. 67-77. DOI: 10.17323/1998-0663.2019.3.67.77

\section{Introduction}

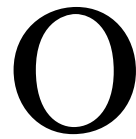
ver the past few decades, the perception and understanding of trust and its role in organizations has significantly progressed. Nowadays, trust is considered to be a highly complicated multy-dimensional phenomenon occuring in many forms, such as interpersonal trust [1, 2], inter-organizational trust [3], intra-organizational trust [2, $4,5]$. Trust is studied from different viewpoints, among which are psycholigical, economic, philosophical and managerial viewpoints [2, 4-6]. Many researchers study trust in different areas including both technological, such as e-business, and non-technological, e.g. political and cultural areas. In spite of lots of exciting ideas and deep insights concerning trust proposed by different researchers and much effort expended, no holistic interdisciplinary approach to trust study has been developed thus far. There is no definition of trust, which most (or at least significant number of) researchers would accept as the common basis in their studies. Instead, almost every researcher proposes his/her own definition of trust, thus making the whole volume of knowledge about trust even more fragmentary and less cohesive [7].

We believe that this is not only due to the complex nature of trust itself, but also to the fact that most researchers adopt narrative and qualitative approaches to the study of trust. Traditionally, research builds upon a statistical analysis of answers to multi-item surveys which are designed to reveal the opinions of respondents on different factors affecting their trust. A review of modern trust study methods, which demonstrates ontological, teleological and epistemological aspects of the research process, which incudes questioning and further qualitative and quantitative analysis, can be found in [5]. Some of the up-to-date methods of trust research, mainly based on different interviewing technics are also presented in [8].

In spite of the fact that the definition derived from such an approach is inevitably biased, it seems to be a widely accepted idea that one cannot manage trust in practice without first formulating a universal trust definition. Lack of progress in constructing the definition therefore results in the lack of studies concerning practical aspects of trust management. This paper adopts an alternative approach. We believe that one can successfully undertake trust building activities without thorough trust definition.

Further on we concentrate on intra-organizational trust only. This kind of trust is relatively well studied [9-14]. A lot of different trust measures have been defined in the literature [7]; some are new concepts, such as the organizational citizenship behavior proposed, and behavioral patterns affecting intra-organizational trust have been studied. A universal definition of intra-organizational trust, however, does not exist, since the coherence of different definitions is still too low [7].

There are only a few studies of trust in the IT area (e.g. [15]); these mainly focus on interorganizational trust in the context of IT outsourcing. As we show below, the results obtained are irrelevant for internal IT organizations and their customers due to principal differences between internal and open markets, where IT organizations and IT companies operate. 
Finally, we find it important to note that after being mainly a topic for academic research trust appears to be becoming a point of interest for commercial companies; they have started offering services related to building, maintaining and measuring trust in organizations [16, 17]. This is yet further evidence of the growing importance of inter-organizational trust building activities.

\section{The aim of the study and statement of the problem}

The aim of this paper is twofold. First, we pro$\mathrm{p}$ se a practical approach to trust management in the specific context of collaboration between an internal IT service provider and its customers. Second, we describe a quantitative non-empirical approach to trust definition in this special case. Our method is based upon the assumption that each organization will develop and use the local trust definition of its own, which most fits its requirements.

We call this definition the trust model. While the universal trust definition may only stem from the experience accumulated by a number of organizations, the trust model is just a local tool, a data structure assisting the members of an IT organization to build trust with business customers and quantitatively estimate the results of this activity.

It is important to note that inter-organizational trust cannot result from the execution of formal business processes, since both the trust itself and trust building activities heavily depend on the individualities of organizational members. Our approach is based upon the following principal assumptions:

1. Trust building is studied in the context of collaboration of organizational roles adopting general organizational policies, business rules and corporate culture, which heavily affects their behavior;

2. The collaborating parties need trust if they cannot predict each other's course of action;

3. Each role has its own unique view on how to achieve trust with its counterparties different from that of other roles.

There are two reasons that we believe that it is important to focus on the trust building between an IT organization and its customers. First, provided there is no reliable business case to decide if IT investments are necessary, a consensus between managers is needed to make an investment decision. If the average level of trust between business managers and an IT organization is high enough, the consensus is more likely to be achieved.

Second, due to the intrinsic complexity of an IT organization's work, most organizational members cannot be considered as IT experts who are able to correctly estimate the quality of IT-related products and services. Moreover, we believe this is true even if an IT organization provides its customers with detailed information on its processes, policies, guiding principles, etc. Trust can help both sides to make a Service Level Agreement, which forms the basis of their collaboration.

One can argue this logic because business units different from the IT organization can be considered to be service providers for their customers as well, even though this approach to organizational analysis is not commonly accepted. There are important differences, however, that make the IT organization unique in its position within the organization. For example, accounting services or HR services are clear even for non-professionals, while the corresponding processes are mostly aligned with external legislative requirements. That's why the organizational members have no reasons to distrust the corresponding business functions. On the other hand, there are business units, which provide complicated professional services, for example, the Technical Directorate at a factory. However, its customers, such as manufacturing managers, are normally technical experts themselves. Their collaboration is not based on trust, because both parties can completely validate each other's ideas. 
The specificity of IT services is that they, on the one hand, are provided to practically every member of an organization and, on the other hand, may require deep professional skills to be correctly estimated. This makes it hard for non-IT professionals to correctly estimate how diligent an IT organization is.

Th strategic importance of trust for an IT organization has already been considered in [8]. The present paper focuses on operational activities, which facilitate permanent maintenance of trust and its support at an acceptable level from the IT organization's side. We further assume that the IT organization adheres to ITSM principles, especially as for Service Level Agreements, which form the basis of the collaboration between an IT organization and its customers.

The following terms will be used below:

- IT organization - an internal IT function of an organization, no matter what form it takes (e.g., a single IT department, group of IT departments or even an independent legal entity);

- internal IT service provider - same as the IT organization;

$\downarrow$ trust building - an activity in the IT organization aimed at earning trust from its customers.

\section{The IT organization and the internal IT service market}

Following [19], we distinguish between different IT service customers and IT service users. At least four groups of customers and users can be identified in an organization:

$\diamond$ participants of business processes who use IT in their everyday work. They are mostly IT service users. The IT service customer in this case is normally one of the business managers responsible for collaboration with IT organization on behalf of a business unit or organization as a whole;

owners and managers of business processes who use IT to improve their respective business processes. A typical IT service for those customers is business process automation;

$\diamond$ senior management and top managers. IT services for these customers include, for example, implementation of corporate-wide IT solutions such as ERP-systems or Master Data Management systems, IT budget optimization, increasing IT organization efficiency or ensuring proper level of information security;

$\diamond$ shareholders and investors. IT services for this category of customers may be intended to increase the return on IT investments. This implies, for example, the use of best practices and proven IT solutions whenever possible, contracting high-class suppliers and so on.

Some business process owners may hold positions as functional managers in the organizational hierarchy. For instance, the owner of the purchasing business process is normally the Head of the Acquisitions business unit, while the owner of the budgeting process is the Head of the Budget or Finance unit etc.

The internal organizational IT service market has some unique features that make it principally different from the open market. The differences are as follows:

$\downarrow$ the IT organization is, by its nature, a monopoly on the market. It provides IT services either on its own or by contracting with external companies on behalf of the organization, thus accumulating all business requirements corporate wide. As a result, the IT organization cannot abandon a service request from any business customer;

$\checkmark$ customers on the open market are able to contract with those IT service providers who render the highest quality services in a specific area. Instead, the customers on the internal market are forced to rely on the single IT service provider which may not be skilled in all areas, to say nothing of the emerging IT-services;

$\checkmark$ customers on the open market use legal commercial agreements to manage relationships with service providers. The Internal Service Level Agreement cannot be used as a legal tool to manage relationships with the IT organization. 
The above specifics of the internal IT service market result in specific relationships between the IT organization and its customers. Both sides may significantly benefit from being trusted partners. For instance, they can:

$\uparrow$ minimize mutual control costs;

$\downarrow$ reduce external risks by solving problems locally without addressing higher positioned managers;

$\downarrow$ adopt long-term relationship models based on agile technologies and task managers instead of traditional project activities.

Since the customers and users of the internal IT service provider are members of the organization and there is a CIO who represents the IT organization for them, we can treat the trust between the IT organization and its customers as a kind of interpersonal trust.

\section{Trust measurement and trust building}

The fundamental review [7] summarizes the most important principles of intra-oraganizational trust measurement. According to [7], most researchers consider intra-organizational trust to be a multi-dimensional notion and trust measurement is treated as the process of a multi-item survey that includes a number of questions or metrics intended to capture different dimensions of trust. The metric specifies one aspect of trust or trust dimension. Metrics are grouped according to the different dimensions. For example, the metric may look like "My colleagues who collaborate with my counterparty consider him/her as trustworth." Since the respondent's perception of a metric is always biased, a kind of averaging is necessary to correctly interpret a respondents' view on the proposed trust dimension. Basically, the trust measurement in accordance with [7] is an approach aimed at constructing a comprehensive trust definition.

Authors of [7] have not discussed a more traditional view of trust measurement such as a quantitative estimation of intra-organizational trust although there are examples of such an approach for the case of inter-organizational trust [16]. Moreover, the authors of [7] revealed a large variety of dimensions and metrics proposed by different authors along with a very limited degree of replication of them by the authors other than their originators.

There are five trust categories that have been recommended in [7] as the most recognized and accurately defined. They therefore can de used as good starting points for future work. These categories correspond to five different statements of the trust research problem. Two categories describe inter-personal trust [20, 21], one the trust among business units and other work groups, the other [22] the trust between a person and his/her subordinates. The last category considers trust as a psychological state, which implies one's intention to accept vulnerability based upon positive expectations of another's intentions. We are interested in the first two categories, which can both be used for our purposes although different in nature.

The first category [20] defines trust as having two dimensions - cognition-based trust and affect based trust. The respective groups of metrics describe the trustor's perception of the ability of the trustee to achieve the expected result and the trustor's confidence in trustee's emotional support and expressions of care and concern for the trustor's welfare.

The second category [21] comprises four dimensions, namely free information exchange, striving for informal agreements, surveillance, and task coordination.

For our purposes, we combine the two categories into a single one that has five of the Now we are ready to proceed to our main goal, i.e. designing a practical method of trust building between the IT organization and its customers. Since the IT organization cannot emotionally affect its customers' behavior, we only can outline its business activities aimed at gaining customers' trust. That's why we further focus 
on information exchange, striving for informal agreements, surveillance, and task coordination from the IT organization's side only. Moreover, the IT organization should manage its customers' cognition-based trust. We also postulate a uniform approach from the ITorganization's side to all its customers.

Table 1 shows the quantitative metrics we have defined for the case of trust building between the IT organization and its customers. They are based on the recommendations of [7] and should not be considered as a complete set of metrics, rather as just an example illustrating the potential ability to develop such metrics.

We assume that the customer's trust is always the combination of two factors: 1) his/her personal trust based on the current and previous experience and/or personal trustfulness, and 2) influence of the customer's environment. Metrics that describe the influence of the environment are italicized in Table 1. We do not analyze an individual customer's behavior, only assume that the metrics in Table 1 help the customer to improve his/her perception of the IT organization, thus resulting in increased trust. The environmental influence is important because a non-IT specialist often cannot identify the true reason of a low value of a metric (for instance, IT service quality or the value of IT risk). Our assumption is that in this case he/she will consult with his/her colleagues to account for their opinions on the IT organization and its work.

The way the customer processes the information received depends on many factors, such as colleagues' trustworthiness, the level of the customer's IT skills, the availability of resources and the desire to control the IT service provider etc. In any case, the IT organization has to account for the influence of the environment and strive to manage it. In other words, the IT organization should be fairly aware of the organizational communication structure.
The foregoing suggests that intra-organizational trust is highly individual for every particular organization by its very nature and depends on the unique structure of inter-personal intimate trust among different members of the organization, including not only customers of the IT organization but also their trusted parties. Moreover, the structure of inter-personal trust is highly volatile over time, which is equally true for the behavior of individual customers. This is the principal challenge to the aforementioned psychometric approach to trust measurement, which uses static surveys to define the trust.

Figure 1 shows an example of an inter-personal trust structure.

The four rectangles in Figure 1 represent four members of an environment (A-D); the arrows indicate information flows. There are two types of information in the flow from A to C, e.g. opinions concerning IT service quality and striving for informal agreements. The levels of trustworthiness of the sources and their respected opinions are shown within the rectangles. This structure does not describe any particular picture of information exchange at a specific moment, but all potential ways the information can flow across the organization, i.e. the historical blueprint of information exchange among customers.

At any particular moment, the degree some customer trusts the IT organization depends on the following reasons:

$\downarrow$ personal perception of current relationships with the IT organization;

$\checkmark$ an individual way of assessment of the information received from the environment;

$\checkmark$ the current state of the inter-personal structure in the organization.

Assume, for example, that customer $\mathrm{C}$ requests opinions of trusted customers $\mathrm{A}$ and B concerning the quality of IT services provided by the IT organization. Generally speaking, the information he/she receives depends 


\section{Quantitative metrics for building trust between the IT organization and its customers}

\begin{tabular}{|c|c|c|}
\hline $\begin{array}{l}\text { Trust } \\
\text { dimension }\end{array}$ & Metrics & Measurement method \\
\hline \multirow{3}{*}{$\begin{array}{l}\text { Cognition-based } \\
\text { trust }\end{array}$} & Quality of IT services & Number of SLA violations \\
\hline & Satisfaction with previous collaboration & Percentage of prolonged SLAs \\
\hline & Percentage of customers satisfied by IT services & An estimate of the share of satisfied customers \\
\hline $\begin{array}{l}\text { Free information } \\
\text { exchange }\end{array}$ & Readiness to share information & $\begin{array}{l}\text { Number of violations of agreements concerning } \\
\text { information access }\end{array}$ \\
\hline \multirow{3}{*}{$\begin{array}{l}\text { Striving } \\
\text { for informal } \\
\text { agreements }\end{array}$} & $\begin{array}{l}\text { Customer's comprehension of the level } \\
\text { of accuracy of system requirements in SLA }\end{array}$ & $\begin{array}{l}\text { Percentage of identified risks approved by } \\
\text { the customer }\end{array}$ \\
\hline & $\begin{array}{l}\text { Customer's comprehension of the requirements } \\
\text { concerning schedule of work and resources needed }\end{array}$ & $\begin{array}{l}\text { Percentage of other customers who approve } \\
\text { the IT organization's plans }\end{array}$ \\
\hline & $\begin{array}{l}\text { Percentage of customers striving to establish } \\
\text { informal relationships with the IT organization }\end{array}$ & An estimate of the share of such customers \\
\hline \multirow{3}{*}{ Surveillance } & $\begin{array}{l}\text { Customer's cost of monitoring the schedule and } \\
\text { work status }\end{array}$ & Analyze customer's information \\
\hline & Customer's cost of quality control & $\begin{array}{l}\text { A profile of divergencies of costs in the quality } \\
\text { plan of the IT organization }\end{array}$ \\
\hline & $\begin{array}{l}\text { Percentage of customers striving to cut costs } \\
\text { of monitoring and control }\end{array}$ & An estimate of the share of such customers \\
\hline \multirow{3}{*}{$\begin{array}{l}\text { Task } \\
\text { coordination }\end{array}$} & $\begin{array}{l}\text { Percentage of changes of work schedule and/or } \\
\text { resources needed initiated by the customer and } \\
\text { waived by the IT organization }\end{array}$ & $\begin{array}{l}\text { Percentage of changes initiated by the customer } \\
\text { and abandoned by other customers presented } \\
\text { in IT organization's work plan }\end{array}$ \\
\hline & $\begin{array}{l}\text { Number of changes of work schedule and/or } \\
\text { resources needed for a customer initiated by the } \\
\text { IT organization and not related to other customers }\end{array}$ & $\begin{array}{l}\text { Analysis of IT organization's internal } \\
\text { documentation }\end{array}$ \\
\hline & $\begin{array}{l}\text { Percentage of customers satisfied with task } \\
\text { coordination with IT organization }\end{array}$ & An estimate of the share of such customers \\
\hline
\end{tabular}

on whether B asked A for a similar opinion. If yes, $\mathrm{C}$ will receive from $\mathrm{B}$ a combination of opinions of B and C, otherwise B's opinion will be highly individual. The structure in Figure 1 does not help to sort out the situation. Customer $\mathrm{C}$ then changes his/her perception of the IT organization depending on the information

Table 1. 
In spite of the fact that the structure in Figure 1 cannot predict the result of communication between the customer and his/her environment, it may help the IT organization to identify those customers who potentially most affect the others, how large are the risks of low quality IT services provided to a particular customer, what groups of customers trust each other most, etc.

This information may prove useful for the internal IT service provider even if the structure is so complicated as not to allow it to analyze each customer's behavior. On the other hand, the structure itself may result from everyday monitoring of stable customers' behavior patterns.

We call this structure the intra-organizational trust model. It is not by any means universal being is relevant for building trust between the IT organization and its customers.

\section{Trust building management and trust model improvement}

Of course, the above arguments should be somehow validated, i.e., compared with the practical experience accumulated in IT organi- zations which attempt to become trusted counterparties for their respective customers. It should be noted that the trust building activity cannot be considered to be a common business process for at least two reasons. First, it heavily depends on the particular individuals involved and their emotional backgrounds. Second, any formal output of the activity may be of no help to trust building since there is no guarantee that this output really affects the customer's trust.

At the same time, it is less likely that any best practices of trust building can exist. This is indirectly supported by the fact that no universal trust definition has yet been found. All of this does not imply, however, that the IT organization is not able to effectively gain the confidence of its customers. To do this, it can follow the principles the well-known process improvement CMMI model [23-25] is based upon. The key idea is to replace the set of process areas in CMMI for Services [24] with the aforementioned intra-organizational trust model. This model becomes more and more validated and standardized in the same way as process areas in CMMI do, while the IT organization proceeds through

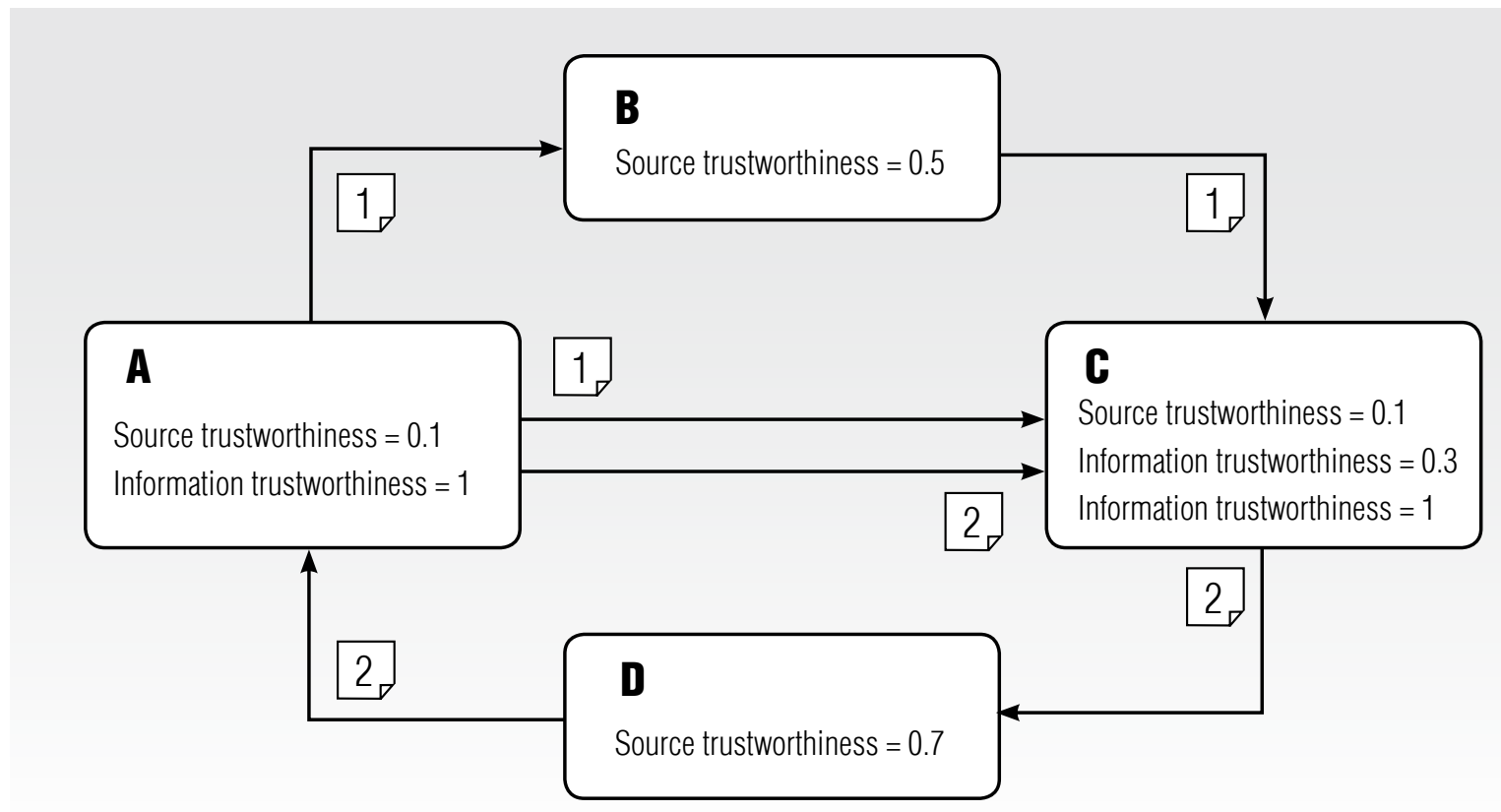

Fig. 1. An example of the inter-personal trust structure 
trust building maturity levels. The trust model at any moment describes the current perception of customers' trust similarly to process areas which describe current institutionalization of business processes. In other words, the maturity level of the IT organization is defined it terms of the accuracy and completeness of the trust model itself and the accumulated experience of its use by IT specialists and IT managers. Note that the IT organization is interested in improving the trust model no matter what happens to the relations with any particular customer and the IT services provided. This is not the case with CMMI process areas that should not be improved unless there are customers interested in such an improvement.

Below is the high-level definition of the maturity levels of the IT organization. It is important to note that in contrast to the universal set of process areas in CMMI for Services, the trust model should be elaborated individually for each organization. The definition below is intended just to outline for IT practitioners an approach based on the trust building maturity assessment and aimed at trust building activity improvement. We identify the following maturity levels:

$\diamond$ incomplete: the very need to intentionally earn customers' trust has not been realized by the IT organization. Trust building activities are spontaneous and incomplete;

initial: There is general understanding of the necessity of trust building. Different IT practitioners gain their customers' trust in different ways. Every customer's increase or decrease in trust is clearly recognized. There is no consensus on how trust should be built, i.e., no common trust model exists;

$\diamond$ managed: the IT organization has elaborated some proven practices of earning the customer's trust. Inter-personal trustful relationships are established between several customers and particular IT specialists. There are internal policies and business rules concerning trust building which are followed by all customer managers in the IT organization. Some elements of the trust model are used to earn some customers' trust;

defined: the IT organization has adopted a common view on how trust has to be built. This view has the form of a single standard trust model. Business rules exist which allow the customer manager to adjust the model to his/her specific relationships with the respective customers.

As was stated above, the trust model assumes that each customer's trust at any moment is known. Obviously, this cannot be achieved through the use of questionnaires and other psychometric technics. There is some indirect evidence, however, which reports on increase/ decrease in trust. The corresponding events can be watched and analyzed. Below are some examples of such events:

- SLA change which introduces higher/ lower level of control from the customer's side;

$\checkmark$ increase/decrease of the number of vertical escalations of problems between the customer and the IT organization;

$\checkmark$ increase/decrease of costs of mutual monitoring and control from a customer's and IT organization's sides;

$\downarrow$ increase/decrease of the number $\downarrow$ of changes from the customer's side without SLA re-assessment;

$\checkmark$ customer's refusal to deal with particular IT specialists.

Of course, the most reliable informal way to become aware of a particular customer's trust is to establish inter-personal trustful contact between the customer and the corresponding customer manager.

At the managed maturity level, the IT organization accounts for trustful relationships between some customers and correspondingly builds relationships with those customers. Trusted IT specialists play a major role in estimating customer's trust. 
At the defined level, the IT organization exercises a common approach to trust building aimed at all current and potential customers, not at a customer of particular interest. The standard trust model is used which accounts for all interactions between customers.

It does not make sense to attempt to describe higher maturity levels at the current stage of understanding the role of the trust model. Any standard model improvement may only be based on real experience in its use, which should be accumulated first. Provided formal trust building business processes do not exist, the trust model looks like a practical alternative allowing one to capture, formalize and analyze the results of trust building activities, even though those activities are informal and vague by their very nature. The trust model may be implemented in a variety of ways from a simple set of files to a sophisticated data structure maintained with the use of formal business processes.

\section{Conclusion}

The approach presented in this paper is just a first step to practical trust management in IT organizations. The main result of the approach is the demonstration of an ability to practically build trust in the absence of a comprehensive definition of intra-organizational trust.

Further steps can only be made by IT practitioners responsible for customers' trust management in IT organizations. It is especially important therefore to get feedback from customer managers, presale managers and other IT specialists involved in customer relationship management. Much preparatory work should be done to elaborate practical tools that would allow them to validate the proposed approach.

The last, but not least challenge is related to the trust management business case. Even though trust benefits seem clear, ensuring a balance between them and the cost of ongoing trust building activities is not a trivial problem.

\section{References}

1. Paliszkiewicz J. (2011) Trust management: Literature review. Management, vol. 6, no 4, pp. 315-331.

2. Feltman C. (2008) The thin book of trust: An essential primer for building trust at work. Bend: Thin Book.

3. Paliszkiewicz J. (2011) Inter-organizational trust: Conceptualization and measurement. International Journal of Performance Meaurement, vol. 1, pp. 15-28.

4. Kramer R., Tyler T. (1996) Trust in organizations: Frontiers of theory and research. Sage Publications.

5. Muhl J.K. (2014) Organizational trust: Measurement, impact and the role of management accountants. Springer.

6. Shaw R.B. (1997) Trust in the balance: Building successful organizations on results, integrity, and concern. San Francisco: Jossey-Bass.

7. McEvily B., Tortoriello M. (2011) Measuring trust in organisational research: Review and recommendations. Journal of Trust Research, vol. 1, no 1, pp. 23-63.

8. Lyon F., Mollering G., Saunders M. (eds.) (2015) Handbook of research methods on trust. Edward Elgar.

9. Zaheer A., McEvily B., Perrone V. (1998) Does trust matter? Exploring the effects of interorganizational and interpersonal trust on performance. Organization Science, vol. 9, no 2, pp. 141-159.

10. Vangen S., Huxham C. (2003) Nurturing collaborative relations. Journal of Applied Behavioral Science, vol. 39 , no 1 , pp. $5-31$.

11. Fulmer A., Dirks K. (2018) Multilevel trust: A theoretical and practical imperative. Journal of Trust Research, vol. 8, no 2, pp. 137-141.

12. Dar O.L. (2010) Trust in co-workers and employee behaviours at work. International Review of Business Research Papers, vol. 6, no 1, pp. 194-204. 
13. Paille P., Bourdeau L., Galois I. (2010) Support, trust, satisfaction, intent to leave and citizenship at organizational level. A social exchange approach. International Journal of Organizational Analysis, vol. 18, no 1, pp. 41-58.

14. Fulmer A., Gelfand M.J. (2012) At what level (and in whom) we trust: Trust across multiple organizational levels. Journal of Management, vol. 38, no 4, pp. 1167-1230.

15. Ali Babar M., Verner J.M., Nguyen P.T. (2007) Establishing and maintaining trust in software outsourcing relationships: An empirical investigation. Journal of Systems and Software, no 80, pp. 1438-1449.

16. Paine K.D. (2013) Guidelines for measuring trust in organizations. Gainesville, FL: Institute for Public Relations, University of Florida.

17. The Ken Blanchard Companies (2017) Building trust. The critical link to a high-involvement, high-energy workplace begins with a common language. Available at: https://www.connexpartners.com/hubfs/assets/ Building\%20Trust.pdf (accessed 15 February 2019).

18. Biryukov A.N. (2017) Strategic management in the IT department. Business Informatics, no 2, pp. $17-24$.

19. The Stationery Office (2011) ITIL Service Strategy, 2011 edition. London, UK: The Stationery Office.

20. McAlister D.J. (1995) Affect and cognition-based trust as foundation for interpersonal cooperation in organizations. Academy of Management Journal, vol. 38, no 1, pp. 24-59.

21. Curral S.C., Judge T.A. (1995) Measuring trust between organizational boundary role persons. Organizational Behavior and Human Decision Processes, vol. 64, no 2, pp. 151-170.

22. Cummings L.L., Bromiley P. (1996) The organizational trust inventory (OTI): Development and validation. Trust in organizations: Frontiers of theory and research. Thousand Oaks, CA: Sage Publications, pp. 302-330.

23. Carnegie Mellon University (2010) CMMI for Development, Version 1.3. CMMI Product Team. Improving processes for developing better products and services. Technical Report. CMU/SEI-2010-TR-033. ESC-TR-2010-033. Pittsburgh, PA: Carnegie Mellon University.

24. Carnegie Mellon University (2010) CMMI for Services, Version 1.3. CMMI Product Team. Improving processes for developing better products and services. Technical Report. CMU/SEI-2010-TR-034. ESC-TR-2010-034. Pittsburgh, PA: Carnegie Mellon University.

25. Carnegie Mellon University (2010) CMMI for Acquisitions, Version 1.3. CMMI Product Team. Improving processes for developing better products and services. Technical Report. CMU/SEI-2010-TR-032. ESC-TR-2010-032. Pittsburgh, PA: Carnegie Mellon University.

\title{
About the author
}

\author{
Alexander N. Biryukov \\ Cand. Sci. (Phys.-Math.); \\ Associate Professor, Department of Business Informatics, \\ Financial University under the Government of the Russian Federation, \\ 49, Leningradskiy Prospect, Moscow 125993, Russia; \\ E-mail: anbiryukov@fa.ru
}

